\title{
A Comparative Analysis of Start-Up Entrepreneurship Support between the UK and Kingdom of Saudi Arabia
}

\author{
Dr. Abdulaziz Abdulmohsen Alfalih \\ Business Administration, CBE - Qassim University, Saudi Arabia \\ E-mail: Afalh@qu.edu.sa
}

Received: August 6, 2020

Accepted: August 18, 2020 Published: August 31, 2020

doi:10.5296/jebi.v7i2.17511

URL: http://dx.doi.org/10.5296/jebi.v7i2.17511

\begin{abstract}
Start-ups in many countries face numerous challenges especially the inadequacy of financial and professional support. Lending to startups is perceived as risky due to the high possibility of business failures. Globally, there is a consensus on the significance of entrepreneurship particularly for social and economic development. Consequently, the correlation between startups and entrepreneurial support has attracted immense interests from researchers and policymakers.

In this paper, the researcher sought to identify the support systems availed to startups in the UK and Sudi Arabia and compare the ease of establishing new businesses between the two countries. A qualitative and quantitative research approach was adopted with a sample of 100 participants from each country. The data collected wasanalysed using statistical package for social scientists (SPSS) and presented in the form of tables and graphs. The results showed that government support systems had a significant impact on the performance of startup entrepreneurship in the two countries under consideration. It was also found that startup entrepreneurship support systems were more favorable in the UK than in Saudi Arabia. In conclusion, the researcher formulated some recommendations for increasing support for startup entrepreneurship in both countries including the provision of practical programs for encouraging entrepreneurial mindsets, especially among learners.
\end{abstract}

Keywords: Saudi Arabia, Entrepreneurship support, Comparative study, Quantitative approach

\section{Introduction}

Saudi Arabia is known to be the largest economy in the Middle East. The country's main revenue is from the petroleum sector which accounts for more than $90 \%$ (Griffiths, Gundry, $\&$ Kickul, 2013, p.345). The fall of the price of oil in the global market has in turn affected 
economic revenue in a negative way, which has impacted negatively also in the economic growth. In order to ensure continuous growth and sustainability, the Saudi Arabia government has put in place various initiatives to diversify the economy and strengthen the oil sector (Cetindamar, Gupta et al., 2012, p.33). Saudi Arabia's vision 2030 release, which is an economic blueprint plan, aims to move away from the central planning and state leadership to open market policies in which private sector and entrepreneurship have been given the major role of leading economic development through competitiveness and job creation (Cetindamar et al., 2012, p.33). Entrepreneurship is the main strategic planning for the country now. The recent introduction of small and medium enterprise authority (SMEA) is a sign that more favorable policies such as starting and doing business are expected to be put in place (Alfaadhel, 2011). Large-scale government programs that focus on access of capital and support for startups have been implemented (Sledzik, 2013).

The challenges faced by entrepreneurs in startups in Saudi Arabia are comparable to those faced in other countries. Due to the bureaucratic government systems and policies, it is often hard for the startups to get into the market (Sledzik, 2013). But, the government of Saudi Arabia has done much to avert the challenges (Stenholm, Acs, \& Wuebker, 2013, p.177). However, the introduction of entrepreneur license and the bankruptcy law has made it easier for companies establish their business to Saudi Arabia due to minimized environmental risks.

This is way, we will try through this research to identify challenges faced by the entrepreneurship effort based on a comparative study between Saudi Arabia and UK in order to provide an exhaustive list of advantages and disadvantages related to this important phenomenon.

This paper will be divided on four main parts: a literature review, a problem research state in order to provide a clear conception of our interest, results and finally discussion to make our findings more useful

\section{Literature Overview}

\subsection{Entrepreneurship}

Entrepreneurship has been widely considered to be the catalyst for economic development which in turn has led to an increase in wealth creation. There are a lot of factors that motivate individuals to start a business. Most people aim to become successful entrepreneurs. The main motivational factor for startups includes the presence of financial support as it enhances the smooth start for a new business (Brychan, 2010). People cannot only rely on financial support since without proper business plan, it may be impossible to stand the test of time; hence the need for counseling and guidance skills from the experts and those already in the market. The motivation to start a new business is usually the originator of entrepreneurship. It also impacts on employment and returns are good if well organized. Sledzik (2013) argued that startup firms could influence the achievement of socio-economic objectives which include poverty alleviation and reduction of dependence ratio.

Startup business needs a lot of support to reduce the chances of failure. The government must 
provide a nurturing environment for these businesses such as efficient and effective physical infrastructure. Legal and economic policies should also be friendly and favorable for the startups (Lepoutre et al., 2013, p.695). According to Marner et al., (2011), the following five elements must be observed to ensure the survival of the startup business: the goods or services; the client; business model; the support team, and financing.

Due to the increase in the unemployment rate in most countries and dwindling of their main economic activities, diversification has been the main option to salvage the situation. Therefore, governments in various countries consider entrepreneurship as a source of wealth creation and provision of employment opportunities (Kidder, 2012).

\subsection{Entrepreneurship Support}

Entrepreneurship support can define as the nurturing environment that is provided for startups which include infrastructure, financial and networking programs. It helps a business to grow and sustain itself in a controlled environment (Pettersen et al., 2015). Entrepreneurship support's main objective is to facilitate maturity of startups. It provides the direction on how those willing to start businesses can access investment opportunities, economic development partnerships, and the state agencies at large.

The entrepreneurship support system is aimed at accelerating development of startups through the support program services. Lawrence et al. (2011) argued that entrepreneurial support must ensure that the startup takes off and sails smoothly and survives to become financially independent. The government and investors in the private sector feel that entrepreneurship support is crucial in helping the weak firms to evade failure (Zamberi Ahmad, 2012, p.220). They offer managerial skill training and technical assistance and access to finance through credit and investors (Koshy, 2010). These factors form the background upon which this research is based and a detailed literature review on these factors will be addressed in the literature section.

\section{Research Problem}

\subsection{Startup Entrepreneurial Support}

Entrepreneurship is about recognition of an opportunity; an evaluation is made on the opportunity then a decision is made to exploit it with the formulation of strategies and to obtain resources. The term startup is directly connected to innovation and progression (Rathaermel, 2012). There are a lot of entrepreneurial support systems in the world. The support systems have adopted different service models. Different markets have got different challenges when it comes to business startups hence the need for different approaches (Hoogendoorn, 2016, p.281). However, many of the challenges are the same such as lags in production capacities, retarded growth, limited financial credit access and lack of proper creativity (Roy, Brumagin, \& Goll, 2014, p.43). For that reason, it is important to improve on the output of support systems as they also investigate their cost management.

\subsection{Startup Research on Saudi Arabia}

The government is offering direct support through its mandated institutions. For example, 


\section{MInstitute ${ }^{\text {Mnk }}$}

Loan Guarantee Program Kafalahoffers bank guarantees to small enterprises (Alrashidi, 2013). The Saudi Public Investment Fund is another institution that is funding startups in the area of technology in collaboration with Japan's Softbank (Harms et al., 2014, p. 365). The government is also indirectly funding nonprofit organisations, universities and entering into a partnership with other corporations to ensure maximum support to startups.

Different corporations are ready to give funding and mentorship programs to various start-ups such as Wa'ed Ventures that provide funding to new enterprises (Fraser, Bhaumik, \& Wright, 2015, p. 76). Besides, it provides training services, business plan formulation, and amenities aimed at supporting them as they grow (Levie, \& Hart, 2011, p.208). Corporations that have learned the importance of technology and innovations for continued improvement are now investing in entrepreneurs that are focused in innovations and inventions in technology. Saudi Arabia government has also divided its support system according to ecosystems which can be referred to as segments or parts under which startups are found and the different institutions that offer support (Salamzadeh \& KawamoritaKesim, 2015).

\section{Riyadh}

It is the most active ecosystem in Saudi Arabia; it is known to be the hub of many of the entrepreneurship support institutions. Most of the capital supplied in Saudi Arabia comes from Riyadh. Though, there are other many capital firms, like Mobility Ventures, ST venture and STC venture and additional funding from the Saudi Arabia government such the Musharakah Program through the matching funds (Cotterill, 2012, p.110). The Riyadh ecosystem can be generally considered to be balanced in terms of support activities and financing.

\section{Jeddah}

It is another ecosystem supporting many industries that are specialised in terms of service and products. The support institutions here include Hikma which concentrates on IP- based startups, Taqadam that focuses on financial technology startups and Flat6Labs which has several supporting systems like, mentorship, funding, and technical training (Estrin, Mickiewicz, \& Stephan, 2011).

\section{The eastern province}

This ecosystem focuses much on technology and academia. The high concentration on advancement in petrochemicals has been influenced by the presence of Saudi Aramco and its several initiatives and the academic attention of the King Fahd University of Petroleum and Minerals (KFUPM) (Estrin, Mickiewicz, \& Stephan, 2011). The entrepreneurship center from Saudi Aramco provides training, incubation, grants, loans and mentorship programs that boost the startups. The capital derived from this ecosystem can be used in investing in the startup of many businesses in different areas such as in health, energy, education and service industry to improve on job creation and economic development (Szerb, Acs, Z., \&Autio, 2013, p.20). For instance, the Saudi Aramco Energy ventures which are a subsidiary of Saudi Aramco has partnered with well-known organisations that are international brands like Google and IBM that provide various support services that include financial and 
non-financial like technology transfer.

\subsection{The Statute of Entrepreneurship Research on Saudi Arabia}

The government in its vision 2030 has outlined some areas that need investments to enhance economic growth.

\subsubsection{Media and E-Commerce}

Saudi Arabia ranks top among the most connected countries with a network penetration of 93\% (Fortunato \& Alter, 2015, p.447). Startups can take this as strength since they can be able to market their products and services effectively through social media platforms such as Facebook, Instagram, and Twitter (Tokila, 2011). The presence of technology is helping the entrepreneurs cut on expenditure such as advertisements and setting up physical shops instead they can market their product using a free online platform and deliver to the customer when an order is placed.

\subsubsection{Health Sector}

With the increase in the number of people that are seeking medical assistance and the government cuts on expenditure, there are a lot of gaps that entrepreneurs can fill in the health sector (Tarek, 2016, p.349). Entrepreneurs can create electronic data records that will facilitate the efficient management of patient records which will be helpful especially to non-governmental institutions that are fighting the chronic diseases (Cotterill, 2011, p. 31). Startups that aim at collecting large forms of data can benefit from the use of the high technology that is available. The data collected can be sold to various organisations to use it.

\subsubsection{Cleantech}

The government is diversifying its energy supply with the demand for solar energy intensifying. With the increase in migration and urbanisation, the need for power is also expected to increase (Autio, 2013). Entrepreneurs are expected to come up with automated usage systems such as sensor appliances that will ensure optimization in energy consumption (Tokila, 2011). Also, startups can come up with cheaper alternatives in water desalination since Saudi Arabia is known to be the world's largest producer of desalinated water.

\subsection{Startup Support on UK}

The UK has the largest number of small firms with a record of 5.2 million (Lorenzi\& Sorensen, 2014). There have been a lot of factors that affect small firms in the UK like taxation policies and regulations, but the accessibility of efficient and effective technology and its adoption has accelerated startups (Tengeh\&Choto, 2015). Currently, technology has made entry into business much easier from all backgrounds compared to the past. For instance, entrepreneurs could use the digital format to find customers and make sales while looking for new adventures.

The desire to be self-employed and be an entrepreneur has motivated startups in the UK rather than necessity (Tarek, 2016, p.350). Usually, the individuals see startup as an opportunity and not an alternative to escape from unemployment. According to the World 
Economic Forum and the World Bank, the UK can be said to be the best place to start a business (Arianoff, 2010).

\subsubsection{Financial Support}

Young entrepreneurs often face the challenge of being sidelined by big financial institutions in terms of loan accessibility. Startups have found it tough to obtain financing from banks since banks have concentrated on lending the already established enterprises because of the lower risk of default involved (Dietrich \&Krafft, 2012). Majority of banks are always risk averse which initially discouraged startups since they were not able to get the funding required.

The government initiative to launch the startup loan company has led to the mushrooming of startups with viable business plans in the country. The company has done more than funding to the startups (Lawrence, Lewis, \& Elsie, 2011). Also, it provides advice through mentorship programs and seminars that will make the entrepreneurs successful. The removal age cap that was put by the government and the increase in funding has led to the rise in the number of startups (Lorenzi \& Sorensen, 2014). Moreover, the introduction of the British Business Bank that was designed to unlock finance to small enterprises encouraged startups (Kidder, 2012). The government has gotten support by private sector investment to increase funds that will be available for financing small businesses. Through the Financial Conduct Authority, the government has put in place policies that govern the financial market by protecting the investors and the small business enterprises (Sledzik, 2013).

Since startups are not only employment oriented but also wealth creation entities which are a source of revenue to the economy, the government of UK launched X-Forces startup Loan Company which funded the ex-military people exclusively (Tengeh \& Choto, 2015). The ex-military communities are individuals with many skills in risk management, specialist technical skills and decision making are crucial in any business management to enable it to excel.

By understanding the importance of entrepreneurship, the government and the private sector have changed much in their attitude towards the startups (Dubos, 2017). Currently, they are supporting them through loan facilities which in turn are encouraging more startups (Hoogendoorn, 2016, p.283). Startups are not only meant for business turnover and growth, but they have a social benefit through employment.

\subsubsection{External Advice on Business Management}

Small enterprises are expected to benefit from external advice, though many small firms do not seek any external help due to the high cost of getting the services. Due to this, the government launched a program that is called Growth Vouchers that provide a subsidy of $50 \%$ to small enterprises (Lepoutre et al., 2013, p.697). Startups now can easily access these services. The external advice has specialist individuals in different areas such as finance, management, marketing, and recruitment. The program is designed to help the small enterprises to overcome any growth barriers that could hinder their success (Zamberi Ahmad, 2012, p.222). The government also has simplified its online advice to small firms through the 
creation of a portal that they can get accurate information. Some of the governmental advice to small firms includes information on legal requirements and regulations, advice on the creation and development of the business idea (Estrin, Mickiewicz, \& Stephan, 2013, p.485). The portal also has information that can help link with specialists and experts (Dubos, 2017).

\section{Research Methodology}

In this section, we will describe the procedure to be followed to explain, reveal, and predict the research phenomenon under analysis. Therefore, this section presents the appropriate research design that was adopted alongside its justification, application, merits, and demerits. The process involved defining the target population and explaining the selected sample. Moreover, this section outlines data used and its sources. Furthermore, this section described the research analysis process, analysis tools, and ethical considerations.

\subsection{Research Design}

In this study, we used a composite approach based on three primary research methods including qualitative, quantitative, and mixed methods could have been employed. The qualitative method entails collecting qualitative data, assessing its depicted trends and critically evaluating such trends to come up with a meaningful conclusion (Dubos, 2017). The qualitative method attempts to understand specific research problems from the perspective of local populace involved. This method is beneficial to extract data related to opinions, behaviours, social contexts, and values of specific populations (Gravetter \& Wallnau, 2016). Some of the strengths of qualitative methods include its capacity to provide comprehensive textual explanations of how the research participants perceive the issue under investigation. Nevertheless, the qualitative method has demerits including the difficult to generalize results due to its small sample size (Autio, 2013).

A quantitative method, on the other hand, is used to collect numerical data and using mathematical and statistical techniques to analyze it as well as drawing conclusions from the findings analyzed. Moreover, quantitative method analyses the correlation between two or more variables to statistically or mathematically present such a relationship (Gravetter \& Wallnau, 2016). The use of the quantitative research method allows for increased objectivity evaluating the findings; hence, the results are not dependent on the study participants' opinions, thoughts, and interpretations. Numerical results can easily be presented using tables, charts, and graphs which allows for better interpretation (Dubos, 2017).

The combination of qualitative and quantitative research design facilitated the smooth flow of different research activities with minimum expenditure on time, money, and efforts (Dubos, 2017). Employing a mixed research design tends to improve merits of the other can outweigh the research as the demerits of the one method. A comparative research design was employed to evaluate the extent of entrepreneurial support between the UK and Saudi Arabia. The use of the design also helped in revealing the characteristics of the explanatory feedbacks obtained from the participants (Autio, 2013). This design was adopted to assess the extent of the explanatory variable when comparing two data sets. This study compares the government 
support availed to entrepreneurial startups between the UK and Saudi Arabia. Outwardly, there were two datasets with explanatory variables under investigation. Descriptive statistics were employed to describe the status of the analyzed variables without adjusting any of them (Gravetter \& Wallnau, 2016). Under the mixed research design, the researcher was able to develop the hypothesis after data collection.

\subsection{Population and Sample}

The research targeted entrepreneurial support in two countries namely the UK and Saudi Arabia. The study noted that most startup entrepreneurs needed financial and professional support from the government and other non-governmental agencies to succeed in the business sector. A sample of 380 participants was considered convenient in this study where half of the sample was drawn from each of the two countries under consideration. The sample comprises one of the several non-probability research units that provide easily accessible data (Tokila, 2011). Convenience sampling used in this study enabled the researcher to obtain the desired sample size in a relatively cheap quick manner (Dubos, 2017). Convenient sampling enabled the researcher to collect information necessary for this research that would otherwise be impossible to obtain if other sampling techniques were applied.

Research requires data collection from either primary or secondary data sources. Primary data is collected by the researcher using specific data collection tools such as questionnaire while secondary data is usually searched and derived from various sources. In this paper, the researcher relied on primary data (Dubos, 2017). Obtaining the primary data involved searching and recruiting willing individuals who were interested or who had already established business startups in the UK and Saudi Arabia in the last 5 years. In the current context of advent computer search tools and information explosion, it was possible to recruit this category of participants via online platforms (Autio, 2013). Therefore, this research was based on primary data collected by questionnaires administered online by email.

\subsection{Analyzing Process}

The fitness of data for the analysis purpose was achieved by carrying out data cleaning and data screening exercises. The data screening exercise entailed inspecting data to identify and eliminate errors and other aspects that needed to be corrected before the conduction of the analysis. The process assisted in identifying missing data and outliers (Gravetter \& Wallnau, 2016). The data cleaning process, on the other hand, entailed error correction and elimination of unnecessary observations identified in the data (Gravetter \& Wallnau, 2016). The cleaning of inaccurate data was facilitated through removing unknown values and correcting the known values. Once, the data was cleaned, it was exported to the SPSS software for the analysis.

The analysis process entailed computing both descriptive and inferential statistics. Descriptive statistics described the general features of the sampled data and revealed the distribution of the variables under the investigation using frequency histograms and tables (Dubos, 2017). The inferential statistics, on the other hand, used the t-test method (Gravetter \& Wallnau, 2016). The t-test method was employed to its simplicity and ease of interpretation. 


\section{Macrothink}

Moreover, the t-test technique revealed the average difference between the two mean samples as well as the degree of significance of the identified difference (Gravetter \& Wallnau, 2016).

To analyze results, we used the SPSS. The SPSS software is ideal for performing statistical analysis and can be understood by individuals with minimum statistical knowledge (Gravetter $\&$ Wallnau, 2016). However, the software can present limitations in a case where advanced modeling and statistical approached are required. In conducting this study, the researcher relied on freely available data from the internet. Therefore, it was ethical for such data sources to be appropriately referenced (Dubos, 2017). Furthermore, data collection depended on humans as primary sources; therefore, it was important to ensure the anonymity of the data used.

\section{Results}

\subsection{Descriptive Statistics}

A descriptive statistic is a summary statistic that quantitatively describes or summarizes features of a collection of information. Data on startup entrepreneurial support between the UK and Saudi Arabia was analyzed, interpreted, and compared.

\subsection{Overall Reliability Test}

Cronbach's alpha is a measure of internal consistency, that is, how closely related a set of items are as a group. It is a measure of scale reliability. A "high" value for alpha does not imply that the measure is uni-dimensional. Cronbach's alpha will generally increase as the intercorrelations among test items increase and is thus known as an internal consistency estimate of reliability of test scores. Because intercorrelations among test items are maximized when all items measure the same construct, Cronbach's alpha is widely believed to indirectly indicate the degree to which a set of items measures a single unidimensional latent construct.

Table 1. Reliability statistics

\begin{tabular}{ll}
\hline Cronbach's Alpha & N of Items \\
\hline 865 & 4 \\
\hline
\end{tabular}

In accordance with reliability check for the study scale that comprise of 4 questions. In SPSS version 22, data has been recorded that have processed for reliability. As above table show that Cronbach's alpha for the study scale appeared resulted .865 of 4 scale items. This result has explained that scale being used in this study is quite efficient for further proceedings.

The results revealed that persons aged between 31 and 40 years were the majority in entrepreneurial start-ups survey. The respondents aged between 41 and 50 years were ranked second with a total of 46 participants while those aged 21 to 30 years took the third position with a total of 43 persons. From these results, age was normally distributed in the sampled 
populations of respondents as evident in the in the graph below. However, those below 20 years were the least in both countries as shown in table 2 and figure 1 below.

Table 2. Respondents' age

\begin{tabular}{|c|c|c|c|c|}
\hline & & \multicolumn{2}{|c|}{ What is your country? } & \multirow[t]{2}{*}{ Total } \\
\hline & & UK & Saudi Arabia & \\
\hline & Under 20 years & 1 & 20 & 21 \\
\hline & $21-30$ years & 44 & 39 & 83 \\
\hline \multirow[t]{3}{*}{ What is your age? } & $31-40$ years & 75 & 38 & 113 \\
\hline & 41-50 years & 42 & 42 & 84 \\
\hline & Above 50 years & 28 & 51 & 79 \\
\hline Total & & 100 & 100 & 380 \\
\hline
\end{tabular}

The frequency histogram revealed that the age variable was normally distributed. This was because the shape was almost similar to a bell although with a slight skewedness to the right. The conclusion was made due to the differences in the lengths of the tails where more respondents fell on the right-hand side.

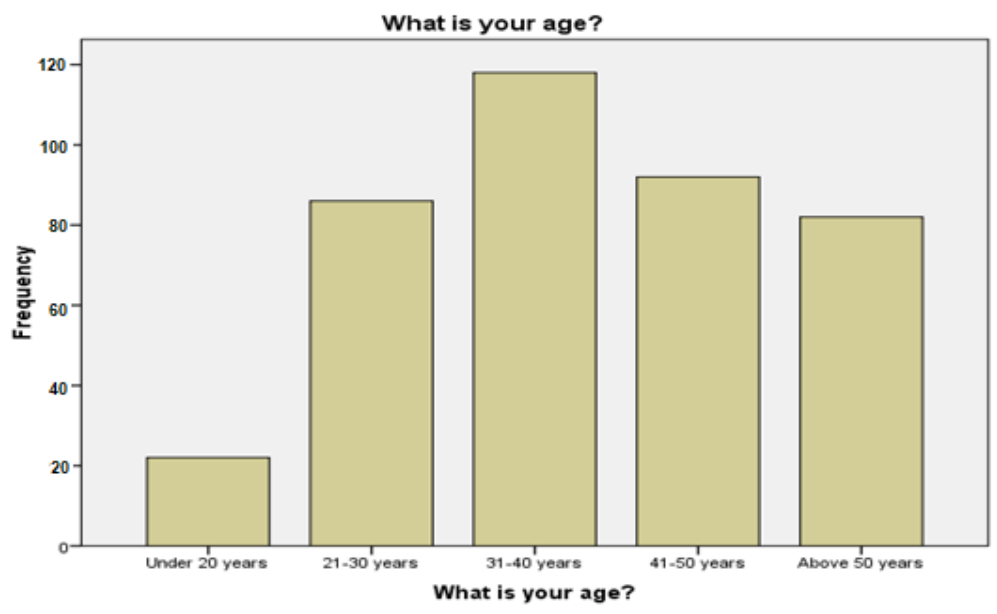

Figure 1. Respondents' age 


\section{Macrothink}

Journal of Entrepreneurship and Business Innovation

ISSN 2332-8851 2020, Vol. 7, No. 2

From the analysis of respondents' responses, it was revealed that females slightly outnumbered males in Saudi Arabia while in the situation was opposite in the UK. From these results, it could be deduced that gender had little influence when it comes to venturing into entrepreneurial startups in either the UK or Saudi Arabia (Tokila, 2011).

Table 3. Respondents' gender

\begin{tabular}{lllll}
\hline & & \multicolumn{2}{l}{ What is your country? } & \multirow{2}{*}{ Total } \\
\cline { 3 - 4 } & & UK & \multicolumn{2}{c}{ Saudi Arabia } \\
\hline What is your gender? & Female & 100 & 103 & 203 \\
& Male & 90 & 87 & 99 \\
Total & & 190 & 190 & 380 \\
\hline
\end{tabular}

Based on the income distribution presented in table 3 below, it was revealed that those with income of between $\$ 1000$ and $\$ 5000$ were the majority accounting for 76 individuals out of the total interviewed followed by those with a monthly income of below $\$ 1000$ and above $\$ 5000$ which recorded same responses of 62 as illustrated in the figure below. From these results, it was evident that venturing into entrepreneurial startups required some capital. However, it is worth noting that income level did not determine the success or failure of startups in both countries (Autio, 2013).

Table 4. Income distribution

\begin{tabular}{lllll}
\hline & \multicolumn{2}{l}{ What is your country? } & Total \\
\cline { 2 - 3 } & UK & Saudi Arabia & \\
Below \$1000 & 50 & 54 & 104 \\
What is your monthly income? \$1000-\$5000 & 79 & 93 & 172 \\
Above \$5000 & 61 & 43 & 104 \\
Total & 190 & 190 & 380 \\
\hline
\end{tabular}




\section{Macrothink}

Journal of Entrepreneurship and Business Innovation

ISSN 2332-8851

2020, Vol. 7, No. 2

The participants with degrees accounted for the highest number of participants cumulatively followed by those with post-graduate degree qualifications as shown in the figure below. High school level of education participants were the least in this survey. In comparison, Saudi Arabians with a degree and post-graduate degree qualifications outnumbered their counterparts from the UK with the same qualifications. The participants with a diploma and high school qualifications were more than those with similar qualifications from Saudi Arabia. From these results, it could be deduced that education played a critical role in the performance of entrepreneurial startups across both countries (Fraser, Bhaumik, \& Wright, 2015, p.79). Comparatively, Saudi Arabian participants had a degree and postgraduate qualifications outnumbering their counterparts from the UK while participants with diploma holders and high school qualifications from the UK outnumbered their counterparts from Saudi Arabia. Starting up a new business required some level of education specially to assist in understanding the support systems available for startups, the regulatory framework, and in identifying the demand gap in the market (Roy, Brumagim, \&Goll, 2014). Therefore, it could be deduced that educated individuals such as those with degrees and diploma had a high level of exposure to the available startup support programs compared to those with high school education level.

Table 5. Respondents' education level

\begin{tabular}{|c|c|c|c|c|}
\hline & & \multicolumn{2}{|c|}{ What is your country? } & \multirow[t]{2}{*}{ Total } \\
\hline & & UK & Saudi Arabia & \\
\hline \multirow{4}{*}{$\begin{array}{l}\text { What is your highest level o } \\
\text { education? }\end{array}$} & High school & 33 & 17 & 50 \\
\hline & fiploma & 56 & 35 & 91 \\
\hline & Degree & 35 & 74 & 109 \\
\hline & Post graduate degree & 58 & 72 & 130 \\
\hline Total & & 190 & 190 & 380 \\
\hline
\end{tabular}

We used a cross-tabulation table shown below to evaluate entrepreneurial experience. The results revealed that those with moderate entrepreneurial experience were the majority across the two countries. However, Saudi Arabia had more highly experienced entrepreneurs than the UK. Entrepreneurial experience plays an important factor in the success of new startups in both countries (Fraser, Bhaumik, \& Wright, 2015, p.81). Based on these results, it could be concluded that Saudi Arabia had more support systems aimed at improving entrepreneurial experience than in the UK. 
Table 6. Level of entrepreneurial experience

\begin{tabular}{|c|c|c|c|c|}
\hline & & \multicolumn{2}{|c|}{ What is your country? } & \multirow[t]{2}{*}{ Total } \\
\hline & & UK & Saudi Arabia & \\
\hline \multirow{4}{*}{$\begin{array}{l}\text { How do you rate your } \\
\text { entrepreneurial experience? }\end{array}$} & Very little experience & 44 & 43 & 87 \\
\hline & Little experience & 39 & 33 & 72 \\
\hline & Moderate experience & 63 & 57 & 120 \\
\hline & Highly experienced & 48 & 53 & 101 \\
\hline Total & & 190 & 190 & 380 \\
\hline
\end{tabular}

\subsection{Entrepreneurship Support in the UK and Saudi Arabia}

The researcher also sought to find out the difference between the entrepreneurial support for startups in the UK and Saudi Arabia was statistically significant. In this case, the researcher used the t-test analysis method to compare the significance of the mean values. Based on the computed mean results, the UK had higher mean value for financial and professional support categories compared to Saudi Arabia. Consequently, the computed t-statistic value for these means was equal to 0.00 . Since the significance value was less than 0.05 (the set significance level), the test rejected the null hypothesis that the difference between the entrepreneurial support available for startups in the UK and Saudi Arabia was insignificant. Therefore, it could be concluded that a significant difference exists between entrepreneurial support between the UK and Saudi Arabia, with the UK providing more entrepreneurial support for startups than in Saudi Arabia. The mean values and t-statistics computations were as shown in the tables 6 and 7 below. 
Table 7. Group statistics 2020, Vol. 7, No. 2

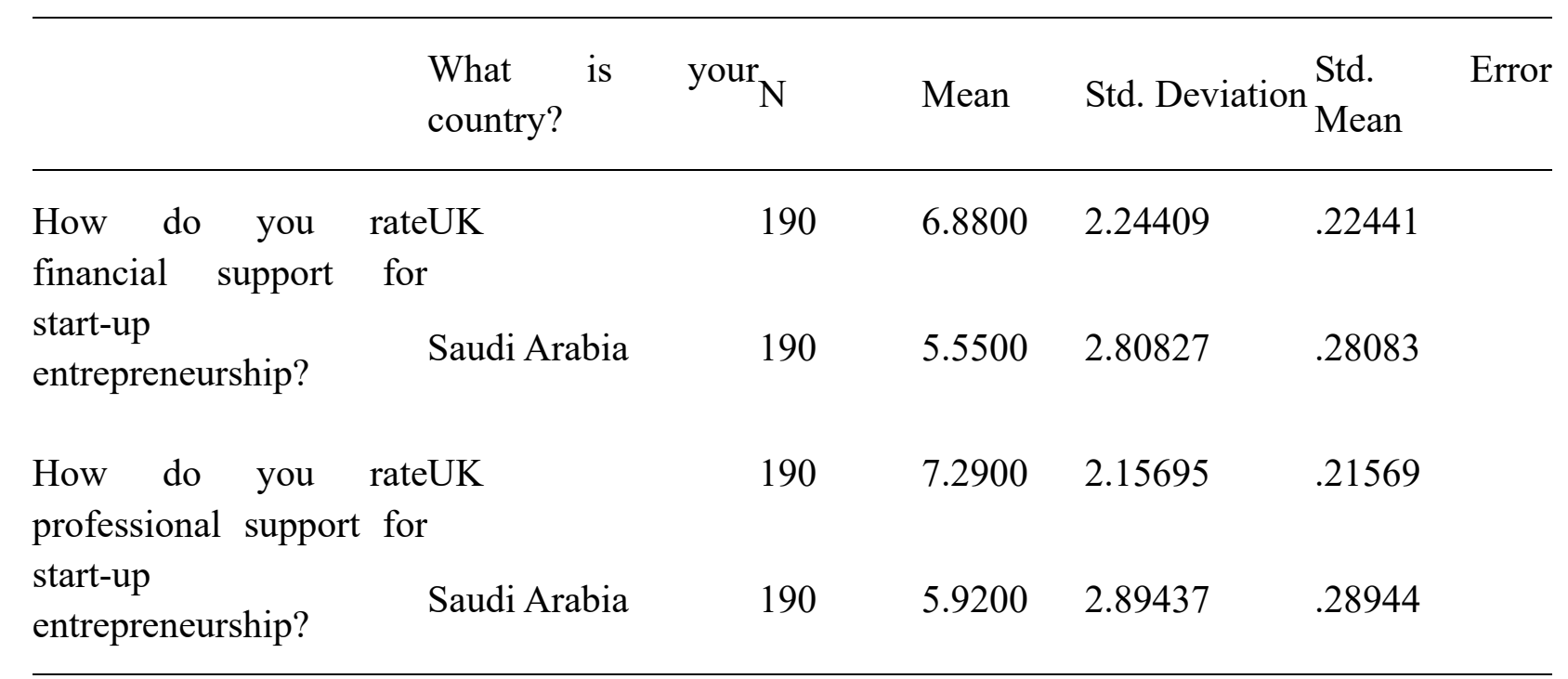

As described by the bar graph below, the financial support for start-up entrepreneurship in the UK was higher than that of the Saudi Arabia. Therefore, there was a need to conduct further analysis using T-test analysis technique to assess whether the observed difference was significant or not. In above association for the financial support for start-up entrepreneurship in the UK was higher than that of the Saudi Arabia. As the significance level ' $p$ ' less than.5 in above table. From the resulted value of R2 it has seen that $22 \%$ effective change reflecting lower level of change effect from independent variable to dependent variable. Financial support services effect for un-standardized coefficient is .6.88.

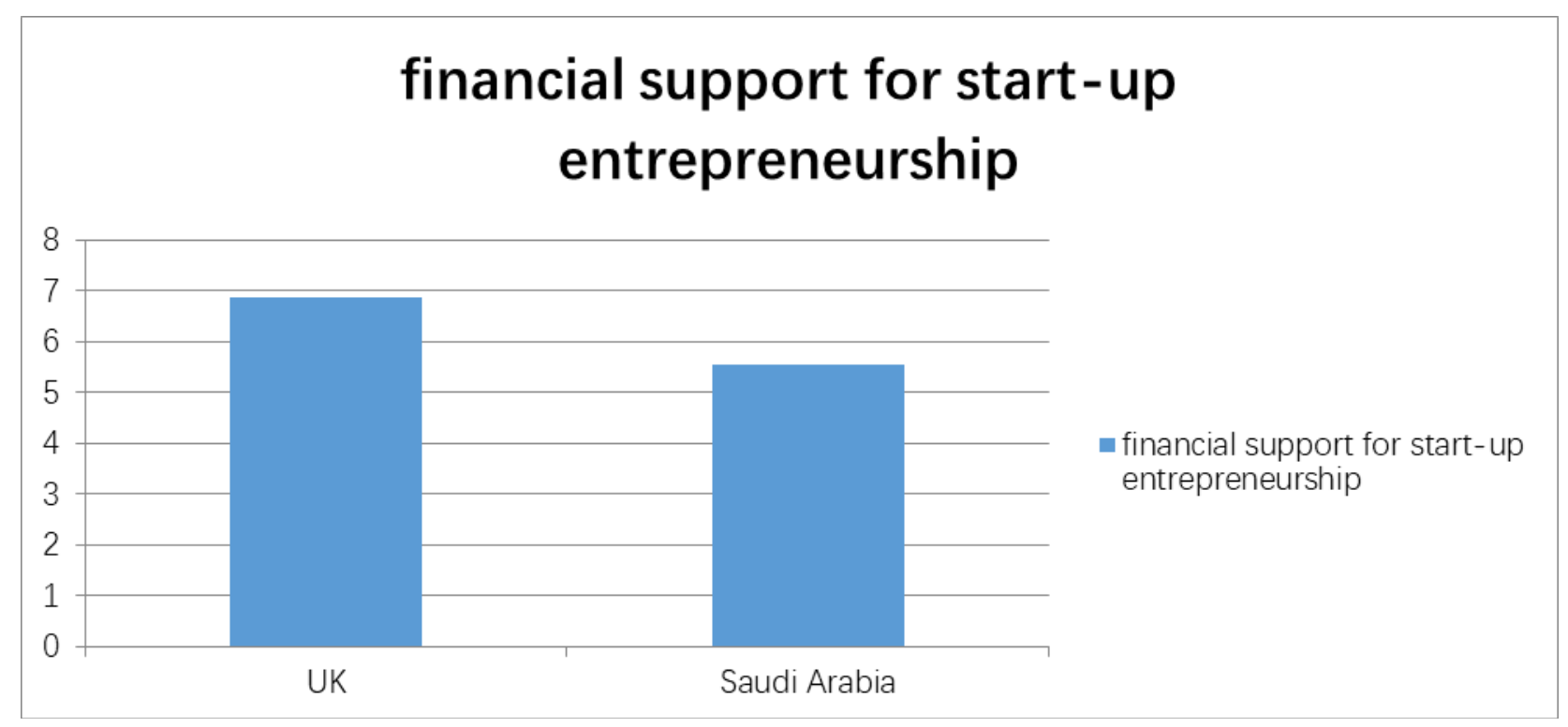

Figure 2. A comparative bar graph showing the financial support for start-up entrepreneurship in the UK and Saudi Arabia 
Table 8. Independent samples tests

Levene's Test for t-test for Equality of Means $_{\text {Equality of Variances }}$ 2020, Vol. 7, No. 2

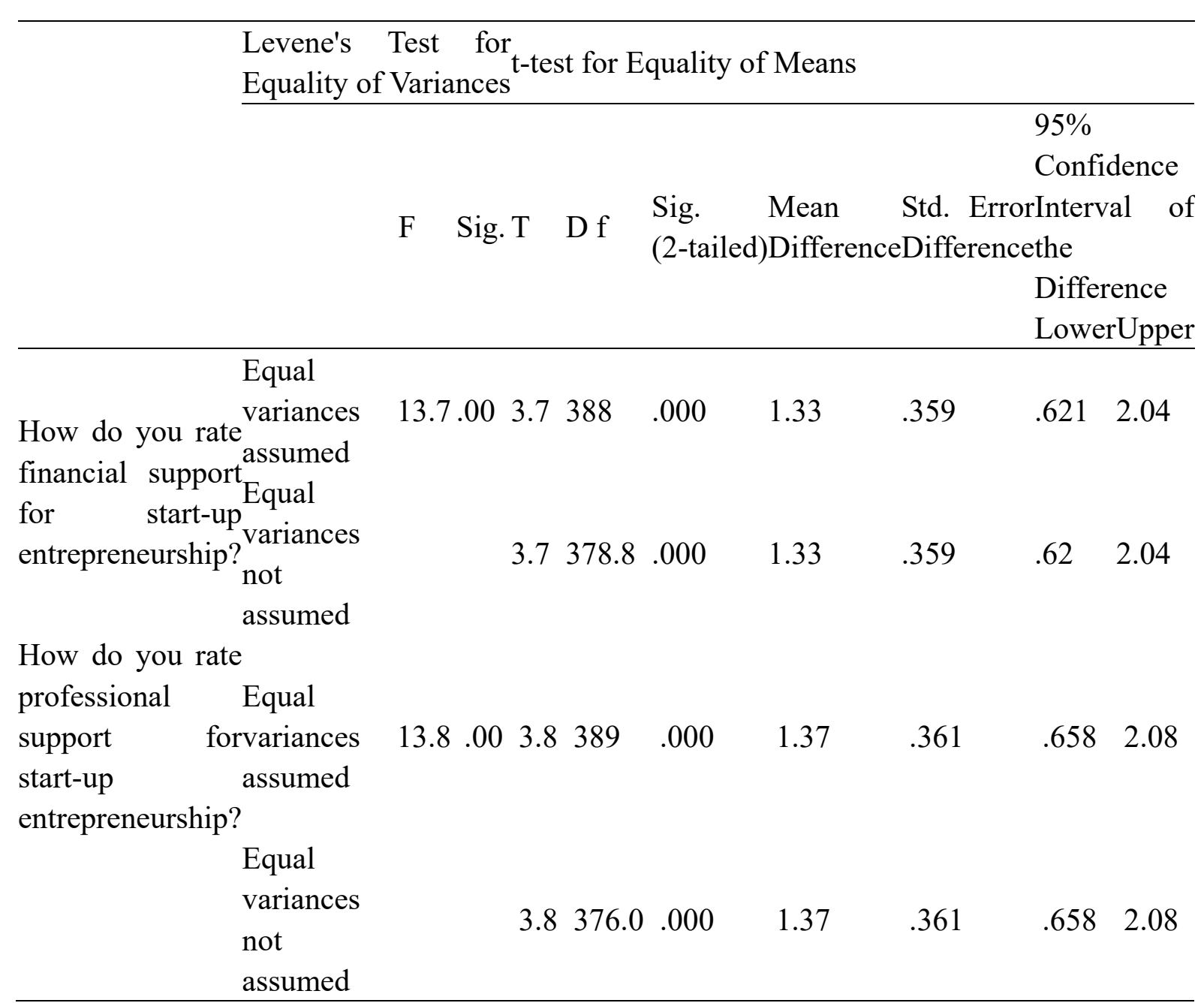

\section{Discussion}

Based on our results, it was revealed that there was considerable entrepreneurial support available in both UK and Saudi Arabia. Nevertheless, the level of entrepreneurial support was higher in the UK than in Saudi Arabia as revealed by the t-statistic value. The major entrepreneurial support included both professional and professional support. From the analysis, both countries had made significant measures to support entrepreneurial startups. In most cases, startups are confronted with several challenges including lack of finances and entrepreneurial skills which cause business failure in the first few years establishment (Stenholm, Acs, \&Wuebker, 2013, p.179). Financial capital tends to be a limiting factor for many startup entrepreneurs due to the lack of affordable sources of capital (Salamzadeh \& KawamoritaKesim, 2015). However, both the UK and Saudi Arabia have made significant efforts to provide affordable sources of finance and professional support to entrepreneurship startups. For instance, the various financial support systems provided in Saudi Arabia including government buy-in, corporation engagement with startups, and support institutions specific to particular segments have been critical in improving entrepreneurial startups.

The UK, on the other hand, introduced several support systems including launching start-up 
loan institutions, removal of age cap for lending to entrepreneurs and provision of professional advice to startup entrepreneurs has gone a long way in encouraging startups in the country (Alrashidi, 2013). In particular, the removal of age cap and less bureaucratic process in starting up a new business in the UK government could be understood as the reason for the high rating of financial support recorded in the analysis section compare to Saudi Arabia.

\section{Conclusion}

In general, entrepreneurial startups are faced by numerous challenges ranging from challenges in accessing capital to inadequate entrepreneurial experiences. Both the UK and Saudi Arabia are not exceptional to such challenges, but the governments in these countries have made significant efforts to address the challenges. In this study, the researcher seeks to identify the various support systems availed by the UK and Saudi Arabia to startups and compare the extent of such support systems in the two countries. From the study, several support mechanisms for startups were identified particularly those related to financial and professional support. Finally, a comparison of the support systems revealed that the UK had better support systems compared to Saudi Arabia.

The following are some recommendation based on the findings of this study. One, the governments should provide practical programs for changing the mindset of their populations about becoming job creators as opposed to waiting to be formally employed (Salamzadeh \& Kawamorita Kesim, 2015). In particular, governments should encourage young adults completing schools to venture into businesses. Such a move could be boosted through incorporating entrepreneurial classes in the school curricula to equip learners with such skills right from early stages in life. Second, this study recommended for the consideration of other factors that affect startup entrepreneurship in the two countries such as whether gender influenced the intention to venture into business (Roy, Brumagim, \&Goll, 2014, p.46). Finally, the researcher recommended the need for future research to investigate how reasons behind the high entrepreneurship failures experienced during the first few years of startups.

\section{References}

Alfaadhel, S. (2011). An empirical study of critical success factors for small and medium enterprises in Saudi Arabia. Challenges and Opportunities (Doctoral dissertation, University of Bradford). https://doi.org/10.1504/IJMED.2006.009083

Alrashidi, Y. A. (2013). Exporting motivations and Saudi SMEs: An exploratory study. World, $3(6)$.

Arianoff, A. (2010). Role of SMEs in the Development of a Region. International Information Centre, 16(5).

Åsvoll, H., \& Jacobsen, P. J. (2012). A case study: Action based Entrepreneurship education how experience problems can be overcome, and collaboration problems mitigated. Journal of Entrepreneurship Education, 15, 75. https://doi.org/10.5465/amle.2012.0107

Autio, E. (2013). Global entrepreneurship and development index 2013. Edward Elgar 
Publishing.

Cetindamar, D., Gupta, V. K., Karadeniz, E. E., \& Egrican, N. (2012). What the numbers tell: The impact of human, family and financial capital on women and men's entry into entrepreneurship in Turkey.Entrepreneurship \& Regional Development, 24(1-2), 29-51. https://doi.org/10.12691/jbe-2-4-1

Cotterill, K. (2011, June). Entrepreneurs' response to failure in early stage technology ventures: A comparative study. In Technology Management Conference (ITMC), 2011 IEEE International (pp. 29-39). IEEE.

Cotterill, K. (2012). A comparative study of entrepreneurs' attitudes to failure in technology ventures. International Journal of Innovation Science, 4(2), 101-116. https://doi.org/10.1260/1757-2223.4.2.101

Dietrich M., \& Krafft J. (2012). Handbook of Economics and Theory of the Firm. UK.

Dubos, R. (2017). Social capital: Theory and research. Routledge. Edward Elgar publishing limited.

Estrin, S., Mickiewicz, T., \& Stephan, U. (2011). For benevolence and for self-interest: Social and commercial entrepreneurial activity across nations.

Estrin, S., Mickiewicz, T., \& Stephan, U. (2013). Entrepreneurship, social capital, and institutions: Social and commercial entrepreneurship across nations. Entrepreneurship theory and Practice, 37(3), 479-504.

Fortunato, M. W., \& Alter, T. (2015). Community entrepreneurship development: an introduction. Community Development, 46(5), 444-455.

Fraser, S., Bhaumik, S. K., \& Wright, M. (2015). What do we know about entrepreneurial finance and its relationship with growth? International Small Business Journal, 33(1), 70-88.

Gravetter, F. J., \&Wallnau, L. B. (2016). Statistics for the behavioral sciences. Cengage Learning.

Griffiths, M. D., Gundry, L. K., \& Kickul, J. R. (2013). The socio-political, economic, and cultural determinants of social entrepreneurship activity: An empirical examination. Journal of Small Business and Enterprise Development, 20(2), 341-357.

Harms, R., Luck, F., Kraus, S., \& Walsh, S. (2014). On the motivational drivers of gray entrepreneurship: An exploratory study. Technological forecasting and social change, 89, 358-365.

Hoogendoorn, B. (2016). The prevalence and determinants of social entrepreneurship at the macro level. Journal of Small Business Management, 54, 278-296.

Huarng, K. H., \& Ribeiro-Soriano, D. E. (2014). Developmental management: Theories, methods, and applications in entrepreneurship, innovation, and sensemaking. Journal of Business Research, 67(5), 657-662. 


\section{Macrothink}

Journal of Entrepreneurship and Business Innovation

ISSN 2332-8851

2020, Vol. 7, No. 2

Kidder, D. (2012). The Start-up Playbook: Secrets of the Fastest Growing Start-ups from their founding Pioneers. California: USA: Chronical Books LLC

Lawrence, A. M., Lewis, D. A. \& Elsie, H. A. (2011) Incubating Success: Incubation best practices that lead to successful new ventures. Institute for research on Labor employment and the economy. USA.

Lepoutre, J., Justo, R., Terjesen, S., \&Bosma, N. (2013). Designing a global standardized methodology for measuring social entrepreneurship activity: The Global Entrepreneurship Monitor social entrepreneurship study. Small Business Economics, 40(3), 693-714.

Levie, J., \& Hart, M. (2011). Business and social entrepreneurs in the UK: Gender, context and commitment. International Journal of Gender and Entrepreneurship, 3(3), 200-217.

Lorenzi, V., \& Sorensen, H.E. (2014). Business development capability: Insights from the biotechnology industry. University of Milan: Bicocca.

Rathaermel, F. T. (2012). Strategic management concepts. New York, McGraw Hill.

Roy, A., Brumagim, A., \&Goll, I. (2014). Predictors of social entrepreneurship success: A cross-national analysis of antecedent factors. Journal of Social Entrepreneurship, 5(1), 42-59.

Salamzadeh, A., \& KawamoritaKesim, H. (2015). Startup companies: life cycle and challenges.

Sledzik, K (2013). Schumpeter's View on Innovation and Entrepreneurship. University of Golansk, Poland.

Stenholm, P., Acs, Z. J., \& Wuebker, R. (2013). Exploring country-level institutional arrangements on the rate and type of entrepreneurial activity. Journal of Business Venturing, 28(1), 176-193.

Szerb, L. A., Acs, Z., \& Autio, E. (2013). Entrepreneurship and policy: The national system of entrepreneurship in the European Union and in its member countries. Entrepreneurship research journal, 3(1), 9-34.

Tarek, B. E. N. (2016). Explaining the intent to start a business among Saudi Arabian University Students. International Review of Management and Marketing, 6(2), 345-353.

Tengeh, R. K., \& Choto, P. (2015). The Relevance and Challenges of Business incubators that Support Survivalist entrepreneurs. Investment Management and Financial Innovations.

Thompson et al., (2010). Crafting and executing strategy (17th ed.). New York, USA: McGraw HillIrwin.

Tokila, A. (2011). Econometric studies of public support to entrepreneurship. Jyväskylä studies in business and economics, (104).

Valdiserri et al., (2010). The study of leadership in business organization: Impact on profitability and organizational success. 


\section{Macrothink}

Journal of Entrepreneurship and Business Innovation

ISSN 2332-8851 2020, Vol. 7, No. 2

Warner A. G. (2010). Strategic analysis and choice: a structured approach. New York, USA: Business expert press

Zamberi Ahmad, S. (2012). Micro, small and medium-sized enterprises development in the Kingdom of Saudi Arabia: Problems and constraints. World Journal of Entrepreneurship, Management and Sustainable Development, 8(4), 217-232.

\section{Appendix}

\section{Questionnaire}

A. Demographic information

What is your age?

\begin{tabular}{|l|l|}
\hline Age & Mark appropriately \\
\hline 1. Under 20 years & \\
\hline 2. $21-30$ years & \\
\hline 3. $31-40$ years & \\
\hline 4. $41-50$ years & \\
\hline 5. Above 50 years & \\
\hline
\end{tabular}

What is your gender?

\begin{tabular}{|c|c|}
\hline 1. Female & Mark appropriately \\
\hline 2. Male & \\
\hline
\end{tabular}

What is your monthly income? 


\begin{tabular}{|l|l|}
\hline Level of income & Mark appropriately \\
\hline 1. Below $\$ 1000$ & \\
\hline 2. $\$ 1000-\$ 5000$ & \\
\hline 3. Above $\$ 5000$ & \\
\hline
\end{tabular}

What is your highest level of education?

\begin{tabular}{|l|l|}
\hline Level of education & Mark appropriately \\
\hline 1) High school & \\
\hline 2) Diploma & \\
\hline 3) Degree & \\
\hline 4) Post graduate degree & \\
\hline
\end{tabular}

How do you rate your entrepreneurial experience?

\begin{tabular}{|l|l|}
\hline Experience level & Mark appropriately \\
\hline 1) Very little experience & \\
\hline 2) Little experience & \\
\hline 3) Moderate experience & \\
\hline 4) Highly experienced & \\
\hline
\end{tabular}

What is your country? 


\begin{tabular}{|l|l|}
\hline Country & Mark appropriately \\
\hline UK & \\
\hline Saudi Arabia & \\
\hline
\end{tabular}

B. Entrepreneurship support

How do you rate financial support for start-up entrepreneurship in the UK?

1- Lowest, 10- highest

\begin{tabular}{|l|l|l|l|l|l|l|l|l|l|l|}
\hline & 1 & 2 & 3 & 4 & 5 & 6 & 7 & 8 & 9 & 10 \\
\hline 1) Financial support & & & & & & & & & & \\
\hline
\end{tabular}

How do you rate financial support for start-up entrepreneurship in the Saudi Arabia?

\begin{tabular}{|l|l|l|l|l|l|l|l|l|l|l|}
\hline & 1 & 2 & 3 & 4 & 5 & 6 & 7 & 8 & 9 & 10 \\
\hline 1) Financial support & & & & & & & & & & \\
\hline
\end{tabular}

How do you rate professional support for start-up entrepreneurship in the UK?

2- Lowest, 10- highest

\begin{tabular}{|l|l|l|l|l|l|l|l|l|l|l|}
\hline & 1 & 2 & 3 & 4 & 5 & 6 & 7 & 8 & 9 & 10 \\
\hline 2) Professional support & & & & & & & & & & \\
\hline
\end{tabular}

How do you rate professional support for start-up entrepreneurship in the Saudi Arabia?

\begin{tabular}{|l|l|l|l|l|l|l|l|l|l|l|}
\hline & 1 & 2 & 3 & 4 & 5 & 6 & 7 & 8 & 9 & 10 \\
\hline 2) Professional support & & & & & & & & & & \\
\hline
\end{tabular}

\section{Copyright Disclaimer}




\section{Macrothink

Copyright for this article is retained by the author (s), with first publication rights granted to the journal.

This is an open-access article distributed under the terms and conditions of the Creative Commons Attribution license (http://creativecommons.org/licenses/by/3.0/). 